\title{
Proposal of dental attention model for children with disabilities in Ecuador
} \author{
Vintimilla Acosta Rafael ${ }^{4}$ \\ ${ }^{1}$ Dentistry research coordinator at Universidad Catolica de Cuenca, South America \\ ${ }^{2}$ Professor of Pediatric dentistry at Universidad Catolica de Cuenca, South America \\ ${ }^{3}$ Professor of Pediatric dentistry at Universidad Catolica de Cuenca, South America \\ ${ }^{4}$ Dentist at ADINEA School, South America
}

Villavicencio Caparo Ebingen ${ }^{*}$, Alvear Cordova Maria Cristina ${ }^{2}$, Pariona Minaya Maria del Carmen ${ }^{3}$ and

Received: 眥 July 17, 2018; Published: 些July 19, 2018

*Corresponding author: Villavicencio Caparo Ebingen, Dentistry research coordinator at Universidad Catolica de Cuenca, Ecuador, South America

\begin{abstract}
Children with disabilities are a vulnerable group that needs special attention and care in dentistry (because of physical, developmental, mental, sensory, behavioral, cognitive or emotional impairment). It is known that disability generates different levels of risk for oral diseases. Ecuador is a country that is at the forefront of global care for people with disabilities, the Catholic University of Cuenca-Ecuador, has proposed an early intervention model (based on evidence) to the control of caries lesions in these patients, through a school based intervention developed at ADINEA school in the same city. This model is currently being applied since August 2017. The purpose of this paper is to present, academically the conceptual model of our intervention. This proposal has 4 principal components parents support, minimal intervention approach, tooth decay control and behavior management.
\end{abstract}

\section{Introduction}

\section{Parents Support}

Good communication among the dentist, patient and parents, builds confidence [1]. Commonly children respond positively when their parent is present in the treatment room [2], The intervention begins with parent's education before the child's dental visit, the procedures must be discussed with them, and this is called the pre-visit conversation [3]. After that, an informed consent [3] is discussed with the parent, informing about the procedures, risks and benefits of the technique that will be used with their child and all the questions are addressed by the professor of pediatric dentistry. All the parents in this school receive this intervention.

\section{Indication of tooth brush}

One of the most important recommendations for parents is the use of fluoride tooth paste when they brush their son's teeth, evidence shows that the fluoride tooth paste effectiveness is like varnishes and gels to prevent caries [4]. Another study shows an efficacy of $23 \%$; $95 \%$ IC $(19 \%$ a $27 \%)$ in prevention of caries prevalence [5]. In this intervention each parent carries their son's tooth brush and the professional modify the handle of the brush according to the specific needs of the child. All the parents in this school receive this intervention.

\section{Oral health education}

A Systematic review shows that traditional oral health was effective in reducing biofilm in school age children, based on this finding our proposal incorporated this kind of educational approach, but addressed to parents. All the parents in this school receive this intervention.

\section{Minimal Intervention Approach}

Traditionally dentists used a dental drill to remove all the decay, however the most relevant evidence shows that this method has a $34.7 \%$ of probability to expose the nerve of the tooth, meanwhile the partial removal method has a $5 \%$ of probability to expose the nerve [2]. This was the reason to incorporate this method in our proposal. All the patients are treated with this philosophy. 


\section{Tooth Decay Control}

\section{Fluoride gel}

The scientifics literature shows that the application of fluoride gel has in permanent tooth a pooled prevented fraction of $28 \%$ (95\% CI $19 \%$ to $39 \%$ ) meanwhile in primary teeth surfaces was $20 \%$ (95\% CI $1 \%$ to $38 \%$ [6].

\section{Dietary control}

Live stile behaviors increase the risk of disease, thus some interventions which are successful in help people to modify some behavior could be an important tool for public health and prevent caries [7]. An RCT study in 1995 demonstrated the effectiveness of sugar restriction in the decrease of $\mathrm{S}$. mutans and $\mathrm{S}$. sobrinus count in plaque of buccal surfaces [8].

\section{Sealants}

Evidence suggest that the children who had sealant applied on molars were less likely to have tooth decay than others. The actual evidence shows that sealants reduces $6 \%$ the development of tooth decay even in 4 years follow up studies [9].

\section{Fluor Varnish}

Scientific literature revealed that It intervention in permanent teeth has a $43 \%$ of efficacy in reduction in decayed surfaces, while in deciduous it has been $37 \%$ efficacy [10].

\section{Atraumatic Restorative Technique (ART)}

This method may reduce pain experience compared with traditional approach (dental drill) 0. 65 mean difference 95\% CI (1.38 to 0.07); but low quality evidence suggest that deciduous tooth treated with ART and high viscosity glass ionomer cement are more likely to result in restoration failure $\mathrm{OR}=1.6 ; 95 \% \mathrm{CI}$ (1.13 to 2.27) [11]; for this reason, after applying this technique, conventional restoration with composite was carried out.

\section{Periodically oral exam}

In children with disabilities this procedure is recommended each three month, and a caries risk assessment should be done [12]

\section{Behavior Management}

\section{Tell-Show-Do (TSD)}

One of the most popular technique in the pediatric dentistry patient management is TSD, The American Academy of Pediatric Dentistry recommend use it, first verbal explanation(tell) should be carried out, after that demonstrations for the patient of the visual, olfactory, auditory and tactile demonstrations should be do (show) and finally proceed with the completion of the procedure (do) [13]. All the children in this school are attended with this intervention.

\section{Live Modelling}

There are some techniques for managing behavior in pediatric dentistry, one of these is the live modelling which is a nonpharmacologic one. In 2009 Farhat-McHayleh, Harfouche and Souaid demonstrated the efficacy in an RCT study; having 11.1 heart beats/min of difference between Tell-Show-Do and a Mother Live modelling technique [14]. All the children in this school are attended with this intervention.

\section{Sedation}

Actual evidence shows that the use of oral midazolam in doses between $0.25 \mathrm{mg} / \mathrm{kg}$ to $0.75 \mathrm{mg} / \mathrm{kg}$ have 1.8 points of effectiveness on the six-point Houpt Behavior scale, demonstrating an association with more co-operative behavior [14]. It is used only if the professional considers necessary.

\section{Physical restraint}

Named Protective stabilization for pediatric dental patients, consist in use some accessories to reduce movements and resistance and increase the cooperation when is providing dental procedures. Aggressive, uncontrolled and impulsive behaviors may harm the professional and the patient, so the physical restraint should be applied with parent permission and informed consent. Not all the children need this intervention, the professional assess the cooperation and recommend use it for or not.

\section{Conclusion}

This proposal of dental attention model for children with disabilities recover actual evidence based recommendations.

\section{References}

1. (2014) American Academy of Pediatric Dentistry. Definition of Special Health Care Needs. Pediatr Dent 35(6).

2. Ricketts D, Lamont T, Innes N, Kidd E, Clarkson J (2013) Operative caries management in adults and children. Cochrane Database of Systematic Reviews 28(3):CD003808.

3. (2014) American Pediatric Dentistry. Guideline on Behavior Guidance for the Pediatric Dental Patient. Pediatr Dent 35(6).

4. Marinho V, Higgins JSA, Logan S (2004) One topical fluoride (toothpastes,or mouthrinses, or gels, or varnishes) versus another for preventing dental caries in children and adolescents. Cochrane Database Syst Rev (1): CD002780.

5. Walsh T, Worthington H, Glenny A, Appelbe P, Marinho V, et al. (2010) Fluoride toothpastes of different concentrations for preventing dental caries in children and adolescents. Cochrane Database Syst Rev (1): CD007868.

6. Harris R, Gamboa A, Dailey Y, A A (2012) One-to-one dietary interventions undertaken in a dental setting to change dietary behaviour. Cochrane Database of Systematic Reviews 14(3): CD006540.

7. Wennerholm K, Birkhed D, Emilson C (1995) Effects of sugar restriction on Streptococcus mutans and Streptococcus sobrinus in saliva and dental plaque. Caries Res 29(1): 54-61.

8. Ahovuo Saloranta A, Forss H, Walsh T, Nordblad A, Mäkelä M, etal. (2017) Pit and fissure sealants for preventing dental decay in permanent teeth. Cochrane Database of Systematic Reviews (7): CD001830.

9. Marinho V, Worthington H, Walsh T, Clarkson J (2013) Fluoride varnishes for preventing dental caries in children and adolescents. Cochrane Database Syst Rev (7): CD002279. 
10. Dorri M, Martinez Zapata M, Walsh T, Marinho V, Sheiham A, et al. (2017) Atraumatic restorative treatment versus conventional restorative treatment for managing dental caries. Cochrane Database of Systematic Reviews (12): CD008072.

11. (2013) Sociedad Española de Epidemiología y Salud Pública Oral. Protocolos para la actuación con niños con alto riesgo de caries en diferentes edades y situaciones. Primera ed. Mateos-Moreno M, editor. Madrid: Universidad Complutense de Madrid.
12. (2016) American Academy of Pediatric Dentistry. Guideline on Behavior Guidance for the Pediatric Dental Patient. Reference manual 37(6).

13. Farhat McHayleh N, Harfouche A, Souaid P (2009) Techniques for managing behaviour in pediatric dentistry: comparative study of live modelling and tell-show-do based on children's heart rates during treatment. J Can Dent Assoc 75(4): 283

14. Lourenço Matharu L, Ashley P, Furness S (2012) Sedation of children undergoing. Cochrane Database Syst Rev (3): CD003877.

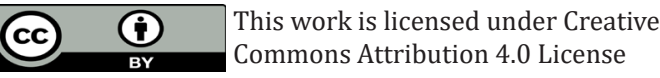

To Submit Your Article Click Here:

Submit Article

DOI: $10.32474 /$ IPDOAJ.2018.01.000125

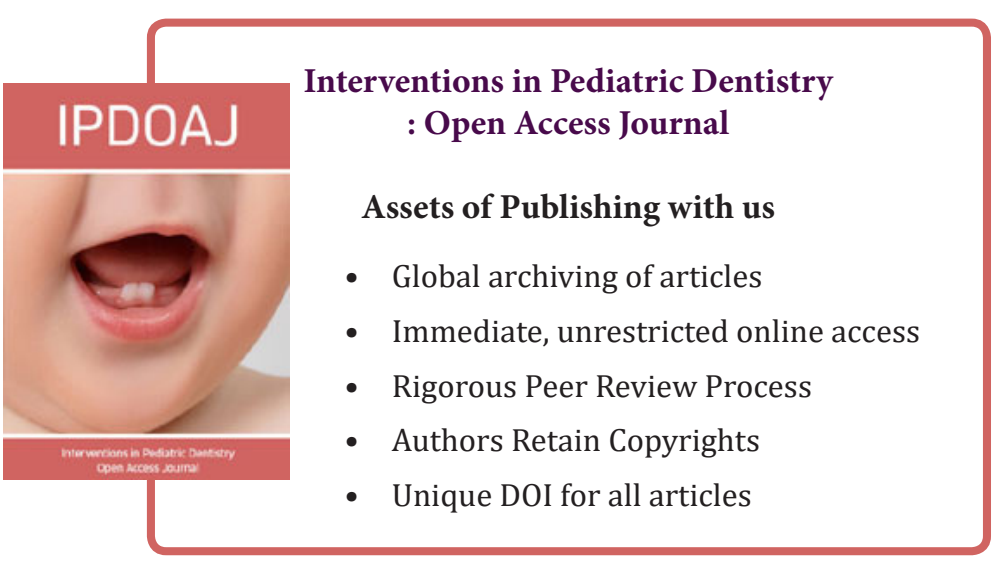

